\title{
Risk factors for progression in children and young adults with IgA nephropathy: an analysis of 261 cases from the VALIGA European cohort
}

\author{
Rosanna Coppo $^{1}$ - Danilo Lofaro ${ }^{2} \cdot$ Roberta R Camilla $^{1} \cdot$ Shubha Bellur $^{3} \cdot$ Daniel Cattran $^{4} \cdot$ H. Terence Cook ${ }^{5}$. \\ Ian S. D. Roberts ${ }^{3} \cdot$ Licia Peruzzi $^{1}$ - Alessandro Amore ${ }^{1}$. Francesco Emma $^{6}$ - Laura Fuiano $^{6}$ - Ulla Berg ${ }^{7}$. \\ Rezan Topaloglu $^{8} \cdot$ Yelda. Bilginer $^{8} \cdot$ Loreto Gesualdo $^{9} \cdot$ Rosaria Polci $^{10} \cdot$ Malgorzata Mizerska-Wasiak $^{11}$. \\ Yasar Caliskan ${ }^{12}$ - Sigrid Lundberg ${ }^{13}$. Giovanni Cancarini ${ }^{14}$. Colin Geddes ${ }^{15}$. Jack Wetzels ${ }^{16}$. \\ Andrzej Wiecek $^{17}$ - Magdalena Durlik ${ }^{18}$ - Stefano Cusinato $^{19} \cdot$ Cristiana Rollino $^{20}$ - Milena Maggio ${ }^{21}$. \\ Manuel Praga $^{22}$ • Hilde K.Smerud ${ }^{23}$ - Vladimir Tesar ${ }^{24}$ - Dita Maixnerova ${ }^{24}$. Jonathan Barratt ${ }^{25}$. \\ Teresa Papalia $^{2} \cdot$ Renzo Bonofiglio $^{2} \cdot$ Gianna Mazzucco $^{26}$ • Costantinos Giannakakis $^{27} \cdot$ Magnus Soderberg $^{7}$. \\ Diclehan Orhan $^{8}$ - Anna Maria Di Palma ${ }^{9}$. Jadwiga Maldyk ${ }^{11}$ • Yasemin Ozluk ${ }^{12}$ • Birgitta Sudelin ${ }^{13}$. \\ Regina Tardanico ${ }^{14}$ - David Kipgen ${ }^{15}$ • Eric Steenbergen ${ }^{16}$ • Henryk Karkoszka ${ }^{17}$. \\ Agnieszka Perkowska-Ptasinska ${ }^{18}$ - Franco Ferrario ${ }^{28}$ - Eduardo Gutierrez ${ }^{22}$. Eva Honsova ${ }^{24}$
}

Received: 15 February 2016/Revised: 3 May 2016 / Accepted: 13 July 2016/Published online: 25 August 2016

(C) IPNA 2016

\begin{abstract}
Background There is a need for early identification of children with immunoglobulin A nephropathy (IgAN) at risk of progression of kidney disease.

Methods Data on 261 young patients [age <23 years; mean follow-up of 4.9 (range 2.5-8.1) years] enrolled in VALIGA, a study designed to validate the Oxford Classification of IgAN,
\end{abstract}

were assessed. Renal biopsies were scored for the presence of mesangial hypercellularity (M1), endocapillary hypercellu larity (E1), segmental glomerulosclerosis (S1), tubular atrophy/interstitial fibrosis (T1-2) (MEST score) and crescents (C1). Progression was assessed as end stage renal disease and/ or a $50 \%$ loss of estimated glomerular filtration rate (eGFR) (combined endpoint) as well as the rate of renal function

The authors of this article acted on behalf of the VALIGA study of the ERA-EDTA Immunonephrology Working Group.

Rosanna Coppo

rosanna.coppo@unito.it

1 Fondazione Ricerca Molinette, Nephrology, Dialysis and Transplantation, Regina Margherita Hospital, Turin, Italy

2 Annunziata Hospital, Cosenza, Italy

3 Oxford University Hospitals, Oxford, UK

4 Toronto General Hospital, University Health Network, Toronto, Canada

5 Imperial College, Hammersmith Hospital, London, UK

6 Bambino Gesù Hospital, Rome, Italy

7 Karolinska University Hospital, Huddinge, Sweden
8 Hacettepe University, Ankara, Turkey

9 University of Bari and Foggia, Bari, Italy

10 Belcolle Hospital, Viterbo, Italy

11 University of Warsaw, Warsaw, Poland

12 University of Istanbul, Istanbul, Turkey

13 Karolinska Institutet, Stockholm, Sweden

14 Spedali Civili University Hospital, Brescia, Italy

15 Western Infirmary Glasgow, Glasgow, UK

16 Radboud University, Nijmegen, The Netherlands

17 Silesian University, Katowice, Poland

18 Warsaw Medical University, Warsaw, Poland 
decline (slope of eGFR). Cox regression and tree classification binary models were used and compared.

Results In this cohort of 261 subjects aged $<23$ years, Cox analysis validated the MEST M, S and T scores for predicting survival to the combined endpoint but failed to prove that these scores had predictive value in the sub-group of 174 children aged $<18$ years. The regression tree classification indicated that patients with M1 were at risk of developing higher time-averaged proteinuria $(p<0.0001)$ and the combined endpoint $(p<0.001)$. An initial proteinuria of $\geq 0.4 \mathrm{~g} /$ day $/ 1.73 \mathrm{~m}^{2}$ and an eGFR of $<90 \mathrm{ml} / \mathrm{min} / 1.73 \mathrm{~m}^{2}$ were determined to be risk factors in subjects with M0. Children aged $<16$ years with M0 and well-preserved eGFR $(>90 \mathrm{ml} / \mathrm{min} /$ $1.73 \mathrm{~m}^{2}$ ) at presentation had a significantly high probability of proteinuria remission during follow-up and a higher remission rate following treatment with corticosteroid and/or immunosuppressive therapy.

Conclusion This new statistical approach has identified clinical and histological risk factors associated with outcome in children and young adults with IgAN.

Keywords IgA nephropathy · Progression · Pathology classification $\cdot$ Proteinuria $\cdot$ Risk factors

\section{Introduction}

IgA nephropathy (IgAN) has variable clinical presentations and different outcomes in both adults and children [1,2]. In countries with active school screening programs, such as Japan, IgAN is most frequently diagnosed by the detection of asymptomatic hematuria, which is considered to be an in early phase of the disease [3], whereas these early cases can be missed in most European and North American countries where proteinuria of more than a trace amount is the common indication for diagnosis by renal biopsy [1]. Although the progression of IgAN to end stage renal disease (ESRD) is slower in children than in adults, probably due to the early diagnosis [4,5], some pediatric patients do progress to ESRD during childhood and many have slower

\footnotetext{
19 Borgomanero Hospital, Borgomanero, Italy

20 San Giovanni Bosco Hospital, Turin, Italy

21 Hospital Maggiore di Lodi, Lodi, Italy

22 Hospital 12 de Octubre, Madrid, Spain

23 University of Uppsala, Uppsala, Sweden

24 General University Hospital, Prague, Czech Republic

25 Leicester General Hospital, Leicester, UK

26 University of Turin, Turin, Italy

27 University of Rome, Rome, Italy

28 Monza Hospital, Monza, Italy
}

but relentless progression during adulthood [6]; hence the urgency for early therapeutic intervention. On the other hand, many childhood cases will never show progression and, importantly, spontaneous remission of mild IgAN has been reported [7]. These observations emphasize the need to determine risk factors for progression of IgAN in children and young adults so that early treatment can be targeted to high-risk individuals to prevent the development of irreversible renal scarring and progressive renal failure [8].

A number of recent studies in children have addressed the value of clinical and pathology variables to predict the risk of progression of renal disease in IgAN using the Oxford-MEST classification of IgAN [9-11]). This classification is based on scores for four pathological features of IgAN: mesangial (M) or endocapillary (E) hypercellularity, segmental glomeru losclerosis (S) and tubular atrophy-interstitial fibrosis (T). All of these published studies included limited numbers of patients and endpoint events [11-16], rendering most of the results from the conventional Cox multivariate analysis non-significant [12-14].

To investigate risk factors for progression of IgAN in young patients, we took advantage of the cohort gathered by the retrospective European multicenter study performed to validate the Oxford Classification (VALIGA; European Validation Study of the Oxford Classification of IgA Nephropathy) [17]. This study enrolled 1147 patients from 13 European countries who were followed over a median of 4.7 years and included 261 children and young adults. These patients had a broad spectrum of clinical presentation and MEST pathology features. Outcome was assessed in this sub-cohort as ESRD or $50 \%$ loss of estimated glomerular filtration rate (eGFR) (combined endpoint) as well as the rate of renal function decline (slope of eGFR).

\section{Materials and methods}

VALIGA was a European multicenter retrospective study of subjects with primary IgAN, with a follow-up $>1$ year or progression to ESRD in $<1$ year [17]. A total of 1147 patients were enrolled in VALIGA and followed over a median of 4.7 years. Patients with Henoch-Schönlein nephritis, chronic hepatitis, diabetes or cancer were excluded. Each renal biopsy was centrally re-scored by the pathology review center in Oxford, UK. Clinical and pathology data were sent to the central database in Turin, Italy. Statistical analysis was undertaken in Cosenza and Turin.

\section{Inclusion criteria, clinical dataset and definitions}

An exploratory analysis was performed in the VALIGA cohort to evaluate the effect of age at renal biopsy as a continuum on the hazard of the combined event (defined as progression to ESRD and/or $50 \%$ loss of eGFR) using the cubic splines (free knots) function [18]. Age (adjusted for sex, 
immunosuppressive treatment, baseline proteinuria and eGFR) had a reasonably linear association with the loghazard of the event until 23 years of age, where the function reaches a peak, changing the slope (Fig. 1). For this reason we selected 216 young subjects aged $<23$ years at renal biopsy [of whom $66.6 \%$ were children $<18$ years)] from the original VALIGA cohort.

In children, eGFR was estimated using the modified Schwartz formula (constant $K=0.55$ ) [19] with a maximum eGFR set at $120 \mathrm{ml} / \mathrm{min} / 1.73 \mathrm{~m}^{2}(17)$ as the accuracy of eGFR for higher values is low and also as small variations in creatinine can have a disproportionate impact on the rate of renal function decline. In subjects aged 1823 years at renal biopsy, eGFR was estimated using the four-variable MDRD (Modification of Diet in Renal Disease) formula [20]. Proteinuria was expressed in grams per day in adults or grams per day per $1.73 \mathrm{~m}^{2}$ in pediatric patients. Mean arterial blood pressure (MAP) was calculated as one-third the pulse pressure [systolic blood pressure - diastolic blood pressure) + diastolic blood pressure]. The MAP in children was standardized to make comparable measurements at different ages $[11,21]$. ESRD was defined as an eGFR of $<15 \mathrm{ml} / \mathrm{min} / 1.73 \mathrm{~m}^{2}$ in all patients. Time-averaged proteinuria (TA-proteinuria) and MAP (TA-MAP) were determined for each year of observation $[17,22]$.
Corticosteroid/immunosuppressive (CS/IS) treatment was considered as intent to treat regardless of the type or duration of CS and/or other IS drugs. Renin-angiotensin system blockade (RASB) indicated treatment with either angiotensinconverting enzyme inhibitors or angiotensin receptor blockers or both.

All renal biopsies were centrally reviewed and scored according to the Oxford Classification [17]:

Mesangial hypercellularity (M): $\mathrm{M} 0 / \mathrm{M} 1, \leq>>50 \%$ of glomeruli with mesangial hypercellularity

Endocapillary hypercellularity (E): E0/E1, absent/present Segmental glomerulosclerosis (S): S0/S1, absent/present Tubular atrophy/interstitial fibrosis (T): T0/T1-2, $\leq 25 /$ $>25 \%$ of renal biopsy tissue.

In addition, in this cohort crescents $(\mathrm{C})$ were assessed as $\mathrm{C} 0$ / C1 (absent/present).

\section{Outcomes}

The clinical outcome was the progression to the combined end point. In addition, the annual rate of renal function decline (eGFR slope) was assessed. We considered as a surrogate

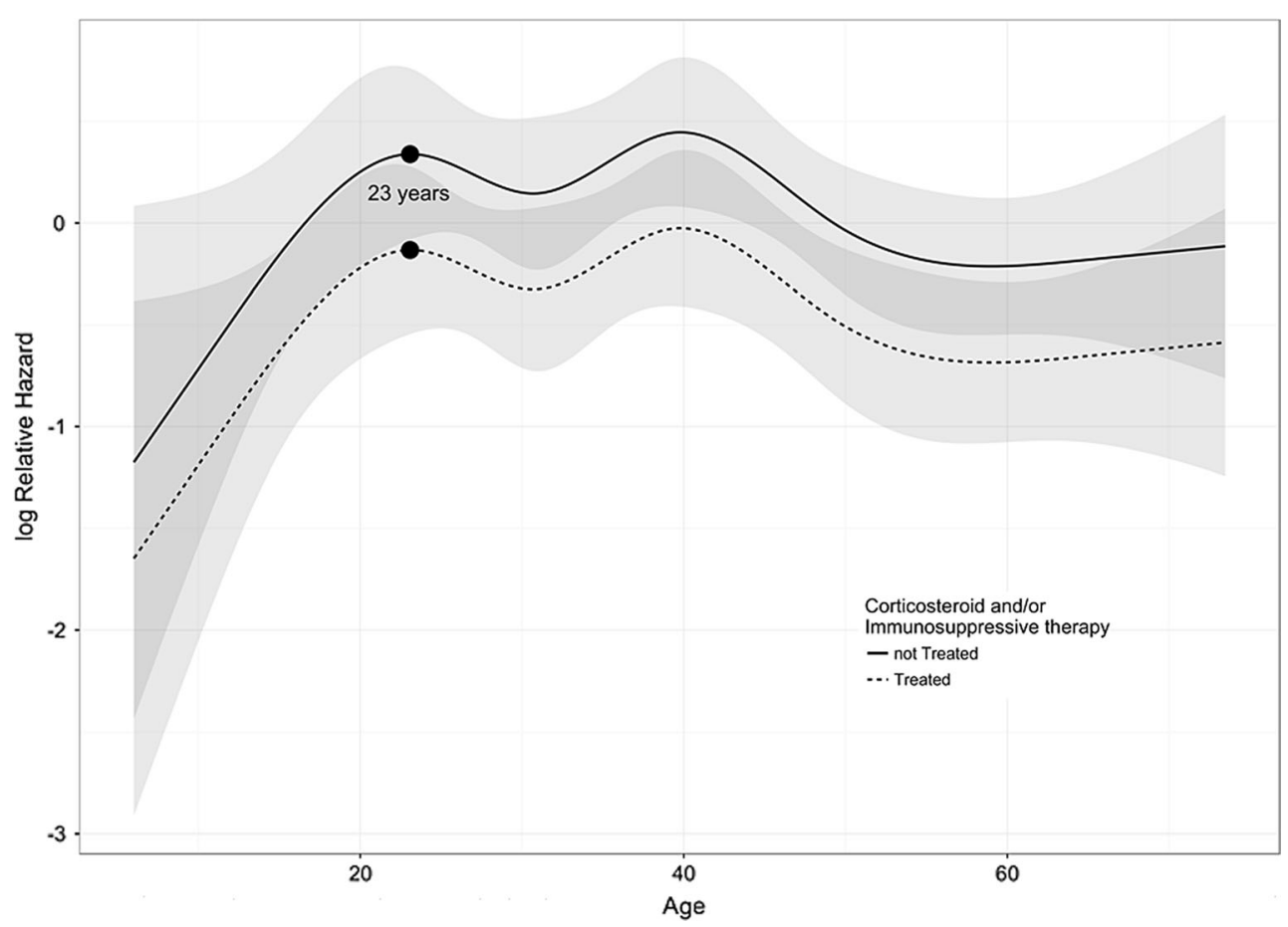

Fig. 1 Effect of age in the VALIGA cohort of 1147 patients with immunoglobulin A nephropathy (IgAN) [17] on the hazard of the combined event [defined as progression to end-stage renal disease (ESRD) and/or $50 \%$ loss of estimated glomerular filtration rate (eGFR)] using the cubic splines (free knots) function. Age (adjusted for sex, immunosuppressive treatment, baseline proteinuria and eGFR) had a reasonably linear association with the log-hazard of the event until 23 years of age, at which point the function reaches a peak, changing the slope 
outcome proteinuria remission defined as reduction in proteinuria over the last year to median values of less than $0.5 \mathrm{~g} / \mathrm{day} /$ $1.73 \mathrm{~m}^{2}$, in patients with initial proteinuria greater or equal to $0.5 \mathrm{~g} /$ day $/ 1.73 \mathrm{~m}^{2}$ at renal biopsy $(17,23)$.

\section{Statistical methods}

Normally distributed variables were expressed as the mean \pm standard deviation and compared using Student's $t$ test, oneway analysis of variance or Pearson's test. Non-normal variables were expressed as the median and interquartile range (IQR) and compared either by the Mann-Whitney, KruskalWallis, or Spearman's test. Categorical variables were expressed as the number (percentage) and compared using the Pearson $\chi^{2}$ test.

The rate of renal function decline was determined by fitting a straight line through available data for eGFR using the principle of least squares. This was plotted and visually examined for each patient. Obvious outliers were censored. Univariate analysis followed by multiple linear regression was used to determine independent predictors of slope. To allow comparison, we used the same multivariate models from the original Oxford Classification study [9]. Survival analysis using Cox regression was performed to test the association between each pathology finding and the combined event, and logistic regression analysis was used for the eGFR slope.

The survival tree model analysis was assessed to identify the predictive power of histological variables as well as cut-off values for continuous factors identified as predictors, taking into account interactions among pathological and clinical features. Tree models are exploratory techniques for uncovering interactions among factors, which define patient subgroups $[24,25]$. As previously described [26], the binary tree is built by repeatedly splitting the patients into two subgroups. At each iteration, all values of all covariates, including MEST scores, are tested, and the variable and the value identifying the most homogeneous outcome in the resulting pair of subgroups are selected automatically without any intervention of the researcher. These subgroups are then split again until they are sufficiently homogeneous in terms of outcome or contain $<10 \%$ of the patients (to avoid extremely small groups). The tree is the representation of this subgroup formation process.

Predictive factors included in the tree models were the pathology variables (M, E, S, T and C), the clinical variables (baseline eGFR, MAP and proteinuria) and the therapy variables (RASB and CS/IS).

To assess the statistical significance of the subgroups identified by tree-based binary models we performed multivariate Cox (in the case of combined event) and logistic (decline in TA-proteinuria) regression analysis based on the outcome to be evaluated. We compared the Cox models using the concordance index (c-index), which is equivalent to the area under the receiving operating curve (AUC).
For all tests a $p<0.05$ value was considered to be statistically significant. All the analyses were performed using $\mathrm{R}$ (version 3.0.1; The R Foundation for Statistical Computing, Vienna, Austria).

\section{Results}

\section{Clinical data and renal pathology features}

The study focused on 261 young subjects aged $<23$ years at renal biopsy (Cohort 1 ) of whom 174 were children aged $<18$ years old (sub-Cohort 2) [Table 1]. The subjects investigated were enrolled from all 13 participating European countries in the VALIGA study [17].

Patients in Cohort 1 (entire study cohort) were 15.27 \pm 4.75 years old at renal biopsy and they were followed for 4.91 (IQR 2.54-8.17) years. The male:female ratio was 2.4:1. Median eGFR was 110.4 (IQR 91.4-120) $\mathrm{ml} / \mathrm{min} /$ $1.73 \mathrm{~m}^{2}$. Most subjects had well-preserved eGFR: $77.0 \%$ were in chronic kidney disease (CKD) stage $1,16.1 \%$ in CKD stage 2, while only $5.4 \%$ were categorized to CKD stages $3 \mathrm{~A}, 3 \mathrm{~B}$ and $1.5 \%$ to $\mathrm{CKD}$ stage 4 . Median proteinuria was $0.9(0.4-2.2) \mathrm{g} / \mathrm{day} / 1.73 \mathrm{~m}^{2}$. MAP was $89.3 \pm$ $10.9 \mathrm{mmHg}$, with $20.6 \%$ of the patients hypertensive and/or receiving anti-hypertensive medications. TA-proteinuria was $0.59(0.3-1.2) \mathrm{g} /$ day $/ 1.73 \mathrm{~m}^{2}$ and TA-MAP was $88.6 \pm$ $8.6 \mathrm{mmHg}$. During the follow-up RASB were started in $69.3 \%$ of the cases and CS/IS initiated in $47.5 \%$ of the patients.

Sub-Cohort 2 (composed of children aged $<18$ years) had a mean age of $12.7 \pm 3.6$ years (only 11/174 children were aged $<6$ years) and were followed for a median of $4.63(2.48-7.35)$ years. TA-proteinuria was 0.56 $(0.27-1.02) \mathrm{g} /$ day $/ 1.73 \mathrm{~m}^{2}$ and TA-MAP was $86.6 \pm$ $8.5 \mathrm{mmHg}$. During the follow-up RASB and CS/IS therapy were started in 66.6 and $50.5 \%$ of the patients, respectively. No significant differences in clinical data were found between the Cohort 1 and the children in sub-Cohort 2.

According to the Oxford Classification criteria, of the entire group of young subjects aged $<23$ years (Cohort 1), $25.7 \%$ showed M1 $12.3 \%$ E1, $50 \%$ S1, $6.8 \% \mathrm{~T} 1-2$ and $13.8 \% \mathrm{C} 1$. These biopsy findings were similar to those found in the subgroup of young children (sub-Cohort 2), of whom $21.8 \%$ showed M1, $13.8 \% \mathrm{E} 1,42.5 \% \mathrm{~S} 1,6.3 \% \mathrm{~T} 1-2$ and $14.9 \% \mathrm{C} 1$ (Table 1).

In the entire study cohort of young subjects aged $<23$ years (Cohort 1) the rate of renal function decline was -0.2 (IQR -2.7 to 0.5 ) $\mathrm{ml} / \mathrm{min} / 1.73 \mathrm{~m}^{2} /$ year (Table 1$) ; 23(8.8 \%$ ) patients reached the combined endpoint of ESRD and/or $50 \%$ 
Table 1 Demographic and clinical data at renal biopsy and during the follow-up period of young subjects $<23$ year-old with immunoglobulin A nephropathy (IgAN) (Cohort 1), including children aged $<18$ years (sub-Cohort 2 )

\begin{tabular}{|c|c|c|}
\hline Variables & $\begin{array}{l}\text { Cohort } 1 \\
(n=261)^{\mathrm{a}}\end{array}$ & $\begin{array}{l}\text { Sub-Cohort } 2 \\
(n=174)^{\mathrm{a}}\end{array}$ \\
\hline \multicolumn{3}{|l|}{ Clinical data at biopsy } \\
\hline Gender, females $(\%)$ & $77(29.50 \%)$ & $49(28.16 \%)$ \\
\hline Age (years) & $15.27 \pm 4.75$ & $12.72 \pm 3.63$ \\
\hline eGFR $\left(\mathrm{ml} / \mathrm{min} / 1.73 \mathrm{~m}^{2}\right)$ & $110.35(91.42-120)$ & $117.02(96.17-120)$ \\
\hline Proteinuria (g/day/1.73 m²) & $0.88(0.38-2.18)$ & $0.84(0.34-2.18)$ \\
\hline MAP (mmHg) & $89.30 \pm 10.98$ & $87.53 \pm 11.35$ \\
\hline \multicolumn{3}{|l|}{ Biopsy features ${ }^{\mathrm{b}}$} \\
\hline M1 & $67(25.67 \%)$ & $38(21.84 \%)$ \\
\hline E1 & $32(12.26 \%)$ & $24(13.79 \%)$ \\
\hline S1 & $131(50.19 \%)$ & $74(42.53 \%)$ \\
\hline $\mathrm{T} 1-2$ & $18(6.89 \%)$ & $11(6.32 \%)$ \\
\hline $\mathrm{C} 1$ & $36(13.79 \%)$ & $26(14.94 \%)$ \\
\hline \multicolumn{3}{|l|}{ Follow-up data } \\
\hline Duration of follow-up (years) & $4.91(2.54-8.17)$ & $4.63(2.48-7.35)$ \\
\hline TA-MAP (mmHg) & $88.55 \pm 8.55$ & $86.64 \pm 8.54$ \\
\hline TA-proteinuria $\left(\mathrm{g} /\right.$ day $\left./ 1.73 \mathrm{~m}^{2}\right)$ & $0.59(0.30-1.19)$ & $0.56(0.27-1.02)$ \\
\hline RASB treatment & $181(69.35 \%)$ & $116(66.67 \%)$ \\
\hline $\mathrm{CS} / \mathrm{IS}$ treatment & $124(47.5 \%)$ & $88(50.57 \%)$ \\
\hline \multicolumn{3}{|l|}{ Clinical outcomes } \\
\hline Rate of eGFR loss (ml/min/1.73 $\mathrm{m}^{2} /$ year) & $-0.17(-2.75$ to 0.48$)$ & $0(-1.72$ to 0.76$)$ \\
\hline 15-year survival free from combined event & $238(91.18 \%)$ & $163(93.68 \%)$ \\
\hline $\begin{array}{l}\text { TA-proteinuria } \leq 0.5 \text { in patients with baseline proteinuria } \\
>0.5 \mathrm{~g} / \text { day } / 1.73 \mathrm{~m}^{2}\end{array}$ & $24 / 154(15.58 \%)$ & $4 / 53(7.54 \%)$ \\
\hline
\end{tabular}

Values are expressed as the mean \pm standard deviation (SD), median with the interquartile range (IQR) in parenthesis or a number with the percentage in parenthesis. No significant difference between the two groups was found

eGFR, Estimated glomerular filtration rate calculated by modified Schwartz or MDRD formula (see Inclusion criteria, clinical dataset and definitions section); MAP, mean arterial pressure; TA, time-averaged; RASB, renin-angiotensin blockade; CS, corticosteroids; IS, immunosuppressive drugs

${ }^{a}$ The study cohort comprised 261 young subjects aged $<23$ years at renal biopsy (Cohort 1) of whom $66.6 \%$ (174) were children $<18$ years (sub-Cohort 2) from the original VALIGA cohort

${ }^{\mathrm{b}}$ MEST-Oxford Classification: M1, mesangial hypercellularity ( $>50$ of glomeruli with mesangial hypercellularity); E1, presence of endocapillary hypercellularity; S1, presence of segmental glomerular sclerosis; T1-2, tubular atrophy/interstitial fibrosis in $\geq 25 \%$ of renal biopsy tissues. C1, Presence of crescents

reduction in eGFR, 14 (5.4\%) developed ESRD, 20 (7.7 \%) had a $50 \%$ reduction in eGFR over the follow-up period and 11 patients $(4.2 \%)$ had both of the endpoints. The estimated survival from the combined endpoint was $69.4 \%$ [95\% confidence interval (CI) 55.9-86] at 15 years. In the pediatric subCohort 2, $11(6.3 \%)$ children reached the combined endpoint, $7(4.0 \%)$ reached ESRD, $8(4.6 \%)$ had a $50 \%$ loss of initial eGFR and $4(2.3 \%)$ had both of the endpoints.

\section{Clinico-pathological correlations}

Univariate analysis of the clinical and histological data at renal biopsy for both Cohort 1 and sub-Cohort 2 indicated that only age $(p<0.001$ and $p=0.007$, respectively) and MAP ( $p=$ 0.003 and $p=0.031$, respectively) were significantly associated with decline in renal function (Table 2). Multiple linear regression models including TA-proteinuria and TAMAP predicted an eGFR slope with higher explained variance $\left(R^{2}=0.228, p<0.0001\right)$ (Table 2).

We investigated the value of the MEST score to predict the rate of eGFR decline as well as the survival to the combined endpoint. In the whole Cohort 1 of patients aged $<23$ years, the E1 lesion was not predictive of outcome, while M1, S1 and T1-2 were predictive both by uni- and multivariate analyses of survival to the combined event, but not of the rate of renal function decline (Table 3). No interaction with treatment was detected. In addition, the presence of crescents $(\mathrm{C} 1)$ was not predictive of survival to the combined endpoint or to progression. When children in sub-Cohort 2 were considered, no MEST score was predictive of progression (eGFR slope or 
Table 2 Correlations between gender, age and clinical data (at baseline and during follow-up) of Cohort 1 and sub-Cohort 2 patients and renal function decline according to univariate and multiple linear regression analyses

\begin{tabular}{|c|c|c|c|c|}
\hline \multirow[t]{2}{*}{ Independent variables } & \multicolumn{2}{|c|}{$\begin{array}{l}\text { Cohort } 1 \\
(n=261)\end{array}$} & \multicolumn{2}{|c|}{$\begin{array}{l}\text { Sub-Cohort } 2 \\
(n=174)\end{array}$} \\
\hline & $R^{2}$ & $p$ & $R^{2}$ & $p$ \\
\hline \multicolumn{5}{|l|}{ Personal characteristics } \\
\hline Age (years) & 0.039 & $<0.001$ & 0.035 & 0.007 \\
\hline Gender (female) & -0.003 & 0.818 & -0.004 & 0.579 \\
\hline \multicolumn{5}{|l|}{ Baseline clinical features } \\
\hline eGFR $\left(\mathrm{ml} / \mathrm{min} / 1.73 \mathrm{~m}^{2}\right)$ & -0.004 & 0.794 & -0.005 & 0.893 \\
\hline MAP (mmHg) & 0.034 & 0.003 & 0.021 & 0.031 \\
\hline Proteinuria $\left(\mathrm{g} /\right.$ day/1.73 $\left.\mathrm{m}^{2}\right)$ & -0.002 & 0.497 & -0.005 & 0.685 \\
\hline \multicolumn{5}{|l|}{ Entire follow-up } \\
\hline TA-MAP (mmHg) & 0.089 & $<0.0001$ & 0.080 & $<0.0001$ \\
\hline TA-proteinuria $\left(\mathrm{g} /\right.$ day $\left./ 1.73 \mathrm{~m}^{2}\right)$ & 0.033 & 0.001 & 0.025 & 0.020 \\
\hline \multicolumn{5}{|l|}{ Multivariate models ${ }^{\mathrm{a}}$} \\
\hline Baseline clinical features & 0.040 & 0.011 & 0.031 & 0.788 \\
\hline Entire follow-up data & 0.228 & $<0.0001$ & 0.229 & $<0.0001$ \\
\hline
\end{tabular}

eGFR, Estimated glomerular filtration rate; MAP, mean arterial pressure; TA, time-averaged

${ }^{a}$ Adjusted for age, gender and baseline eGFR

Table 3 Correlations between pathological features and outcomes in Cohort 1 and sub-Cohort 2 patients

\begin{tabular}{|c|c|c|c|c|c|c|c|c|}
\hline \multirow{3}{*}{$\begin{array}{l}\text { Pathological features included } \\
\text { in the MEST-Oxford } \\
\text { Classification }^{\mathrm{a}}\end{array}$} & \multicolumn{4}{|c|}{ Cohort $1(n=261)$} & \multicolumn{4}{|c|}{ sub-Cohort $2(n=174)$} \\
\hline & \multicolumn{2}{|c|}{ Rate of renal function decline } & \multicolumn{2}{|c|}{$\begin{array}{l}\text { Survival from combined } \\
\text { event }\end{array}$} & \multicolumn{2}{|c|}{ Rate of renal function decline } & \multicolumn{2}{|c|}{$\begin{array}{l}\text { Survival from combined } \\
\text { event }\end{array}$} \\
\hline & $\begin{array}{l}\text { Univariate }(\mathrm{ml} / \\
\min / 1.73 \mathrm{~m}^{2} / \\
\text { year) }\end{array}$ & $\begin{array}{l}\text { Multivariate } \\
\beta(\mathrm{SD})^{\mathrm{b}}\end{array}$ & $\begin{array}{l}\text { Univariate } \\
\mathrm{HR}(95 \% \\
\mathrm{CI})\end{array}$ & $\begin{array}{l}\text { Multivariate } \\
\mathrm{HR}(95 \% \\
\mathrm{CI})^{\mathrm{c}}\end{array}$ & $\begin{array}{l}\text { Univariate }(\mathrm{ml} / \\
\min / 1.73 \mathrm{~m}^{2} / \\
\text { year) }\end{array}$ & $\begin{array}{l}\text { Multivariate } \\
\beta(\mathrm{SD} .)^{\mathrm{b}}\end{array}$ & $\begin{array}{l}\text { Univariate } \\
\mathrm{HR}(95 \% \\
\mathrm{CI})\end{array}$ & $\begin{array}{l}\text { Multivariate } \\
\mathrm{HR}(95 \% \\
\mathrm{CI})^{\mathrm{c}}\end{array}$ \\
\hline \multicolumn{9}{|l|}{ Mesangial proliferation } \\
\hline M0 & $-1.42 \pm 7.97$ & & 1 & 1 & $-0.85 \pm 7.34$ & & 1 & 1 \\
\hline M1 & $-2.71 \pm 7.32$ & $0.37(0.96)$ & $\begin{array}{c}3.88(1.69- \\
8.88)\end{array}$ & $\begin{array}{c}2.80(1.21- \\
6.50)\end{array}$ & $-1.46 \pm 8.38$ & $1.40(1.32)$ & $\begin{array}{c}2.71(0.79- \\
9.35)\end{array}$ & $\begin{array}{c}1.60(0.35- \\
7.27)\end{array}$ \\
\hline$p$ & 0.243 & 0.70 & 0.001 & 0.016 & 0.659 & 0.293 & 0.114 & 0.544 \\
\hline \multicolumn{9}{|l|}{ Segmental glomerulosclerosis } \\
\hline S0 & $-0.89 \pm 5.38$ & & 1 & 1 & $-0.47 \pm 5.07$ & & 1 & 1 \\
\hline $\mathrm{S} 1$ & $-2.60 \pm 9.58$ & $-0.29(0.83)$ & $\begin{array}{c}3.51(1.30- \\
9.47)\end{array}$ & $\begin{array}{c}3.48(1.24 \\
9.76)\end{array}$ & $-1.68 \pm 9.99$ & $-0.23(1.08)$ & $\begin{array}{c}2.70(0.79- \\
9.27)\end{array}$ & $\begin{array}{c}2.45(0.61- \\
9.88)\end{array}$ \\
\hline$p$ & 0.076 & 0.73 & 0.013 & 0.018 & 0.297 & 0.831 & 0.114 & 0.016 \\
\hline \multicolumn{9}{|c|}{ Tubular atrophy/interstitial fibrosis } \\
\hline T0 & $-1.59 \pm 7.53$ & & 1 & 1 & $-0.84 \pm 7.01$ & & 1 & 1 \\
\hline $\mathrm{T} 1-2$ & $-3.83 \pm 10.99$ & $-0.85(1.75)$ & $\begin{array}{c}5.31(2.18- \\
12.95)\end{array}$ & $\begin{array}{c}3.49(1.39- \\
8.76)\end{array}$ & $-3.06 \pm 13.67$ & $1.81(2.49)$ & $\begin{array}{c}2.86(0.61- \\
13.3)\end{array}$ & $\begin{array}{c}0.55(0.08- \\
3.88)\end{array}$ \\
\hline$p$ & 0.242 & 0.627 & $<0.001$ & 0.008 & 0.349 & 0.468 & 0.18 & 0.545 \\
\hline
\end{tabular}

CI, Confidence interval; HR, hazards ratio; eGFR, Estimated glomerular filtration rate

${ }^{a}$ M1, Mesangial score $>0.5$; S1, any segmental sclerosis; T1-2, tubular atrophy and interstitial fibrosis of $>25 \%$. For more detail, see Inclusion criteria, clinical dataset and definitions section and Table 1 footnote

${ }^{\mathrm{b}}$ Multivariate linear models are adjusted for age, gender, initial eGFR, follow-up blood pressure and proteinuria

${ }^{\mathrm{c}}$ Multivariate Cox regression models are adjusted for follow-up blood pressure and proteinuria 
the combined endpoint) by univariate analysis. Similarly, there was no association between MEST or C scores and the combined endpoint by CS/IS treatment in sub-cohort 2 (children).

\section{Survival tree analysis}

Survival tree analysis was performed in the entire Cohort 1 to detect subgroups of patients with survival from the combined event (Fig. 2). Four subgroups of patients were identified based on survival free from the combined event. A subgroup of 58 patients with M0 and baseline proteinuria of $<0.4 \mathrm{~g} /$ day $/ 1.73 \mathrm{~m}^{2}$ had a 15 -year survival of $100 \%$ (Reference Group; Fig. 2A). The subgroup of 67 young subjects presenting with M1 were found to have the highest risk (Fig. 2D), with a 15-year survival of $46.8 \%$ [95 \% confidence interval (CI) 28.0-78.1, $p<0.001$ vs. Reference Group, defined above). Patients with $\mathrm{M} 0$ and baseline proteinuria of $\geq 0.4 \mathrm{~g} /$ day $/ 1.73 \mathrm{~m}^{2}$ were divided into two groups based on baseline eGFR: those with a baseline eGFR of $<88.6 \mathrm{ml} / \mathrm{min} / 1.73 \mathrm{~m}^{2}$ (Fig. 2C) showed a 15-year survival of $56.5 \%(95 \% \mathrm{CI}$
$29.8-100.0 ; p=0.002)$, and those with a baseline eGFR of $>88.6 \mathrm{ml} / \mathrm{min} / 1.73 \mathrm{~m}^{2}$ (Fig. 2B) showed a 15 -year survival of $82.8 \%$ (95\% CI $67-100.0 ; p=0.06$ ). The c-statistics revealed a good discrimination using the tree model (cindex $0.81,95 \%$ CI $0.71-0.92$ ) which was higher than, but not statistically different from, a Cox regression model built with the same covariates (c-index $0.76,95 \% \mathrm{CI}$ $0.63-0.88$ ).

A second regression tree analysis was developed to look at the MEST score, initial eGFR and the association with different levels of TA-proteinuria (Fig. 3). Again, the 67 young patients presenting with M1 (Fig. 3E) constituted the subgroup presenting with the highest levels of TA-proteinuria (median 1.22, IQR $\left.0.61-2.41 \mathrm{~g} / \mathrm{day} / 1.73 \mathrm{~m}^{2} ; p<0.001\right)$. Those presenting with M0 and an eGFR of $<89.6 \mathrm{ml} / \mathrm{min} / 1.73 \mathrm{~m}^{2}$ (Fig. 3D) at biopsy had a median TA-proteinuria of 0.74 (IQR $0.59-1.19$ ) $\mathrm{g} /$ day $/ 1.73 \mathrm{~m}^{2}$. Both these subgroups showed a follow-up proteinuria that was significantly higher than those patients with $\mathrm{M} 0$, an eGFR of $\geq 89.6 \mathrm{ml} / \mathrm{min} /$ $1.73 \mathrm{~m}^{2}$ and age of $<12.2$ years at diagnosis (Fig. 3A).

A third classification survival tree analysis (Fig. 4) was performed on the 154 young subjects presenting with

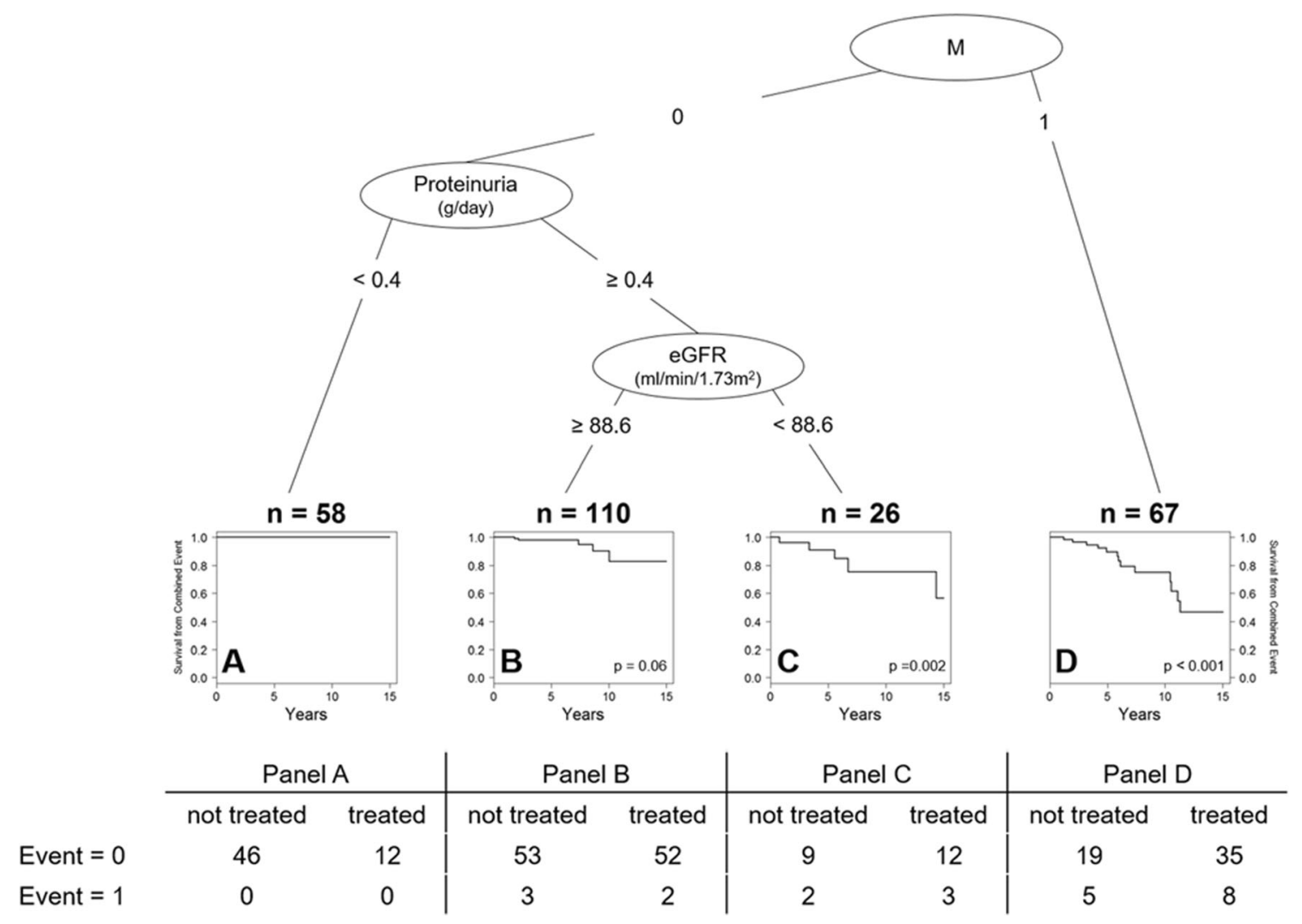

Fig. 2 Survival tree for classification of 15-year survival from the combined event (progression to ESRD and/or $50 \%$ loss of eGFR) in Cohort 1 (patients with IgAN, aged $<23$ years). Panels A-C Identified subgroups (A Reference Group), showing the Kaplan-Meier curves for the patients of the subgroups and the $p$ value of the log-rank test vs. those of the Reference Group. The number of patients is indicated above the

panels. The number of patients treated with corticosteroids/ immunosuppression of survivors and non-survivors to the combined event is given below the panels. $M$ Mesangial hypercellularity (MEST-Oxford Classification): $0 / 1 \leq>>50 \%$ of glomeruli with mesangial hypercellularity. eGFR, Estimated glomerular filtration rate; ESRD, end stage renal disease; IgAN, immunoglobulin A nephropathy 


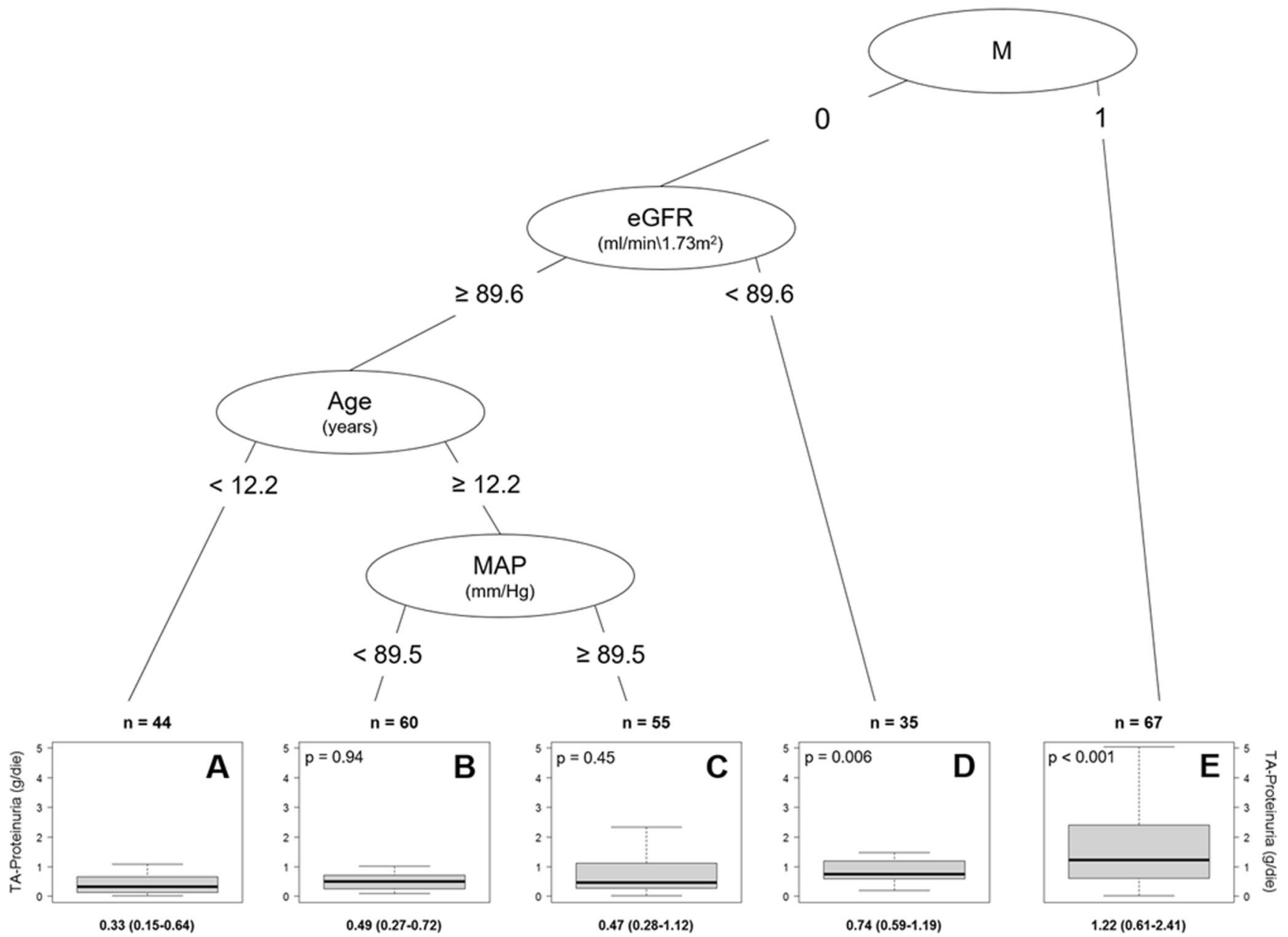

Fig. 3 Survival tree for classification of TA-proteinuria levels in Cohort 1 patients. Panels A-E Identified subgroups (A Reference Group), showing the time-averaged (TA)-proteinuria levels [median and interquartile range (IQR) are given below each panel] for patients in subgroups and the $p$ value of the post-hoc Tukey HSD test vs. those of the Reference Group. The number of patients is indicated above each panel. MAP Mean arterial blood pressure proteinuria of $\geq 0.5 \mathrm{~g} /$ day $/ 1.73 \mathrm{~m}^{2}$ in order to identify subgroups of patients with different probabilities of remission to a TA-proteinuria over the last year of $<0.5 \mathrm{~g} /$ day $/ 1.73 \mathrm{~m}^{2}$. Three subgroups showed a very low proportion of remission: subgroup 1, comprising patients older than 16.4 years $(4 / 70$ remissions, $p<0.0001$ vs. Reference Group; Fig. 4A); subgroup 2, comprising younger patients with M1 (1/25; $p<0.0001$; Fig. 4 b); subgroup 3, comprising patients younger than 16.4 years with $\mathrm{M} 0$ and a baseline eGFR of $\leq 90.4 \mathrm{ml} /$ $\min / 1.73 \mathrm{~m}^{2}(1 / 13 ; p=0.005$; Fig. $4 \mathrm{C})$. Among the patients younger than 16.4 years with M0 and a baseline eGFR of $>90.4 \mathrm{ml} / \mathrm{min} / 1.73 \mathrm{~m}^{2}$, those who did not receive any IS treatment had a moderate probability of remission $(8 / 30 ; p=0.02$; Fig. 4d), while those who were treated with steroid/IS drugs showed a higher remission rate (10/16; Reference Group; Fig. 4E). The c-statistics showed a good discrimination of the tree classification model (AUC 0.8, $95 \%$ CI 0.69-0.9, Youden Index 0.534) which was comparable to a logistic regression model built with the same covariates (AUC 0.77, $95 \%$ CI 0.7-0.87, Youden Index 0.462; Fig. 5).

\section{Discussion}

In the present study we used a new statistical approach, namely, survival tree-based modeling $[24,25]$ to identify combined clinical and histological risk factors for disease progression that is valid for both children and young adults with IgAN. The results confirm the value of the MEST scores in predicting survival to the combined endpoint of ESRD or $50 \%$ loss of eGFR in young subjects aged $<23$ years enrolled in the VALIGA study and also provide new insights on the prognostic value of the combination of MEST and clinical factors for children aged $<18$ years.

The variability of outcome in children with IgAN ranges from remission to progression to $\operatorname{ESRD~[7,~16,~27,~28],~which~}$ 
emphasizes the need to identify clinical and histological risk factors for progression. The original Oxford study included a limited number of children (56 cases from four continents) which was inadequate for direct sub-analysis, but the interaction with age suggested that the predictive value of the MEST score in children was similar to that in adults [11]. Nationallevel or single-center studies from Japan [12], China [13] and Sweden [14] (enrolling 161, 218 and 90 children, respectively) aimed at validating the predictive value of the Oxford classification in children with IgAN confirmed the value of some - but not all — of the MEST scores by univariate analysis. However, when multivariate Cox regression models were adjusted for data at renal biopsy (eGFR, MAP and proteinuria), no individual feature maintained an independent predictive value, apart from the MEST T lesions in Chinese pediatric patients. The Swedish validation study found significant predictive value for some scores ( $\mathrm{ME}$ and $\mathrm{T}$ ) only in models constructed by combining one histological lesion with proteinuria at renal biopsy or at 1-year follow-up. If clinical variables were not added, only models including two histological variables provided significant prediction by multivariate Cox analysis [14]. The Japanese validation study used an endpoint of eGFR of $<60 \mathrm{ml} / \mathrm{min} / 1.73 \mathrm{~m}^{2}$ instead of the combined endpoint adopted in all of the other studies, hence limiting the possibility of comparison. This study reported a significant predictive value for MEST T lesions only in multivariate models, which included two histological variables. The presence of $>30 \%$ crescents was significant only in multivariate models including proteinuria at biopsy [12].

The analysis of 174 VALIGA children (aged $<18$ years) from 13 European countries, given the broader spectrum and larger numbers of cases, was predicted to more reliably determine the predictive value of the MEST score in children. The initial analysis failed to identify an association between pathological features and the combined outcome or with eGFR decline over time. The children enrolled in VALIGA included mild cases, with minimal proteinuria and acute glomerular lesions, similar to the features noted in the Japanese cohort, in which an early endpoint was used. These lesions are potentially reversible after steroid/immunosuppressive treatment, a treatment given to more than half of the European children. However, no interaction with therapy was detected, possibly due to the limited number of subgroups of treated and untreated children and/or the small number of outcome events. Indeed, the lack of predictive value of the histological lesions by multivariate analysis in almost all of the pediatric studies may be related to inadequate statistical power. In the Japanese cohort the endpoint of eGFR of $<60 \mathrm{ml} / \mathrm{min} / 1.73 \mathrm{~m}^{2}$ was reached in only $4.3 \%$ of children [12]. In the Chinese cohort, the combined endpoint was attained by $12.4 \%$ of children [13] and in the Swedish study, by $18 \%$ of subjects. In our VALIGA pediatric sub-Cohort the combined endpoint was reached in only 11 children ( $6.3 \%$ of cases). Analysis of the prognostic value and interaction of clinical and pathology risk factors in children may be of limited statistical significance given these reasons. This may be addressed in the future by pooling individual pediatric IgAN databases with adult databases, as recently performed [29]. These considerations were our incentive to test a novel statistical approach using the VALIGA data.

By analyzing the outcome of VALIGA patients according to patient age at renal biopsy, we observed that the hazard of the combined endpoint in both treated and untreated young subjects increased with age until a plateau was reached at 23 years. This may reflect a high capacity of recovery - either spontaneously or due to therapy - in young subjects which seems to change with age. Hence we performed the analysis of combined clinical and pathological risk factors in subjects aged $<23$ years. We used a new statistical approach, survival tree-based modeling, which offers an unbiased identification of subgroups of young patients with IgAN with particular risk profiles for progression. The accuracy of the newly adopted model proved to be equal to that of previous approaches, as the discrimination of the tree model, indicated by the c-index, was similar to the Cox regression model built with the same covariates. In addition, this analysis allowed the identification of important factors, which combined clinical and pathology variables, associated with the chosen endpoint. Moreover, it suggests it is possible to identify statistically valid predictive cut-off values for continuous variables. For example, instead of pre-defining levels of proteinuria as risk for progression, this tree-based binary analysis automatically calculates the threshold level for the outcome.

We observed that young subjects presenting with M1 or proteinuria at $>0.4 \mathrm{~g} /$ day $/ 1.73 \mathrm{~m}^{2}$ are at higher risk for IgAN progression. This risk is higher in patients even with a mild reduction in eGFR of $<90 \mathrm{ml} / \mathrm{min} / 1.73 \mathrm{~m}^{2}$ at the time of renal biopsy. This is the first time that a multivariate analysis has detected a threshold for proteinuria at renal biopsy in association with a reduction in renal function: the combination of these two risk factors could be easily applied in clinical practice.

The tree analysis also provided important data in children aged $<16$ years with IgAN without mesangial hypercellularity (M0) and well-preserved eGFR ( $>90 \mathrm{ml} / \mathrm{min} / 1.73 \mathrm{~m}^{2}$ ), showing this pediatric patient population has a high probability of proteinuria remission during follow-up. Moreover, in this subgroup of children, the benefits of CS/IS therapy reached statistical significance. Again, these results, if confirmed, have important implications for clinical practice.

In conclusion, the tree-based analysis can potentially identify combinations of risk factors in young subjects with IgAN, unbiased from pre-determined cut-off values. This approach could be of value to pediatricians managing IgAN patients.

This study has several limitations that have to be considered (30). First of all, this is not a purely pediatric data analysis 


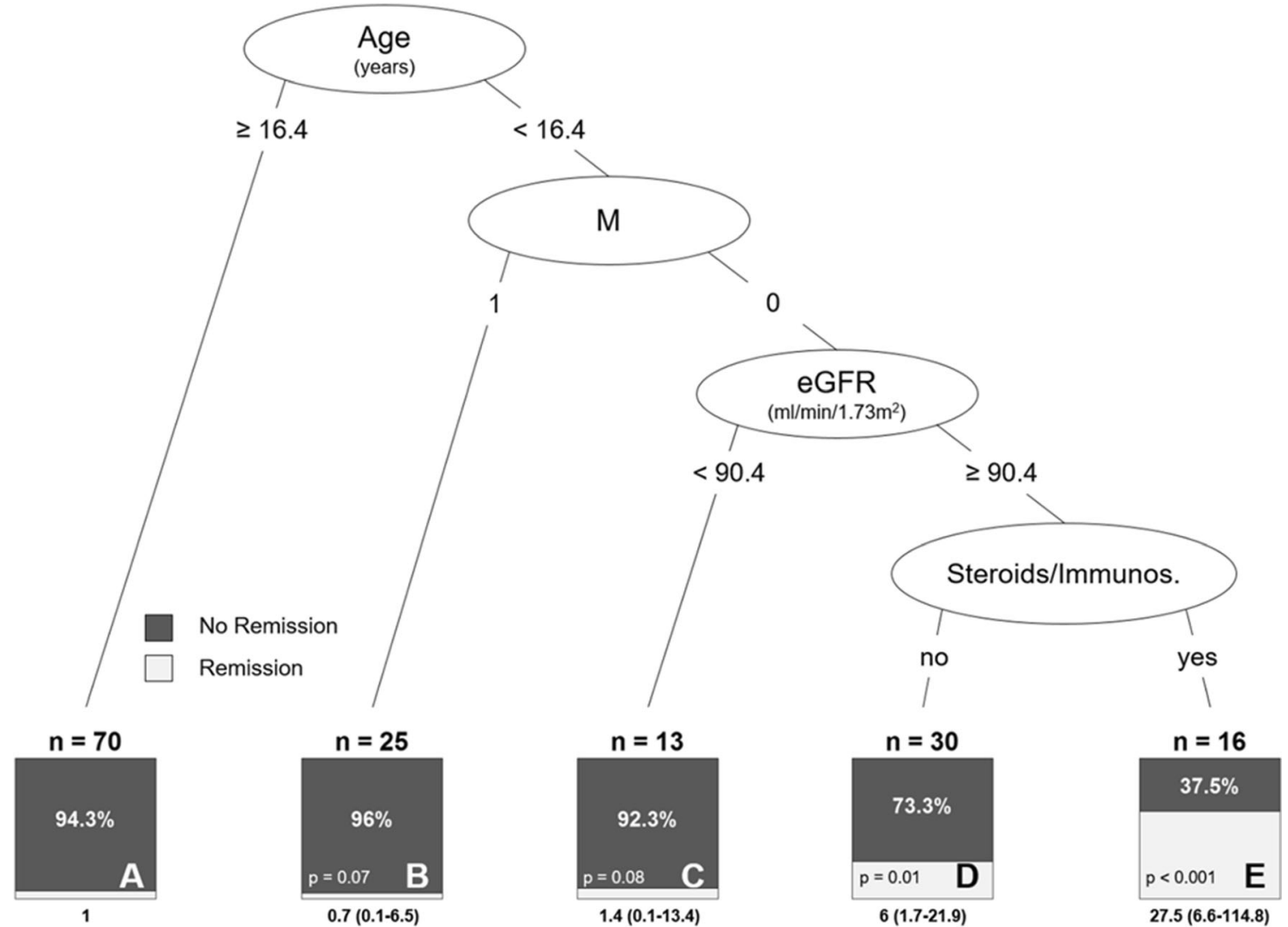

Fig. 4 Survival tree for classification of the 154 young patients in Cohort 1 with a proteinuria of $\geq 0.5 \mathrm{~g} /$ day $/ 1.73 \mathrm{~m}^{2}$ at biopsy and showing a remission to a TA-proteinuria of $<0.5 \mathrm{~g} /$ day $/ 1.73 \mathrm{~m}^{2}$. Panels A-E, Identified subgroups (A Reference Group), showing the percentage of proteinuria remission and the $p$ value of the logistic regression model with subgroups as independent variable. The odds ratio with the $95 \%$ confidence interval (CI) in parenthesis of each identified group vs. the Reference Group is reported below the panels, and the number of patients is indicated above the panels. Immunos Immunosuppression therapy
Fig. 5 Receiver operating characteristic curve $(R O C)$ for classification tree in Fig. 4 (area under the ROC curve (AUC) 0.804, $95 \%$ CI 0.699-0.904) and a logistic model built with the same variables (AUC 0.774, $95 \%$ CI 0.697-0.871)

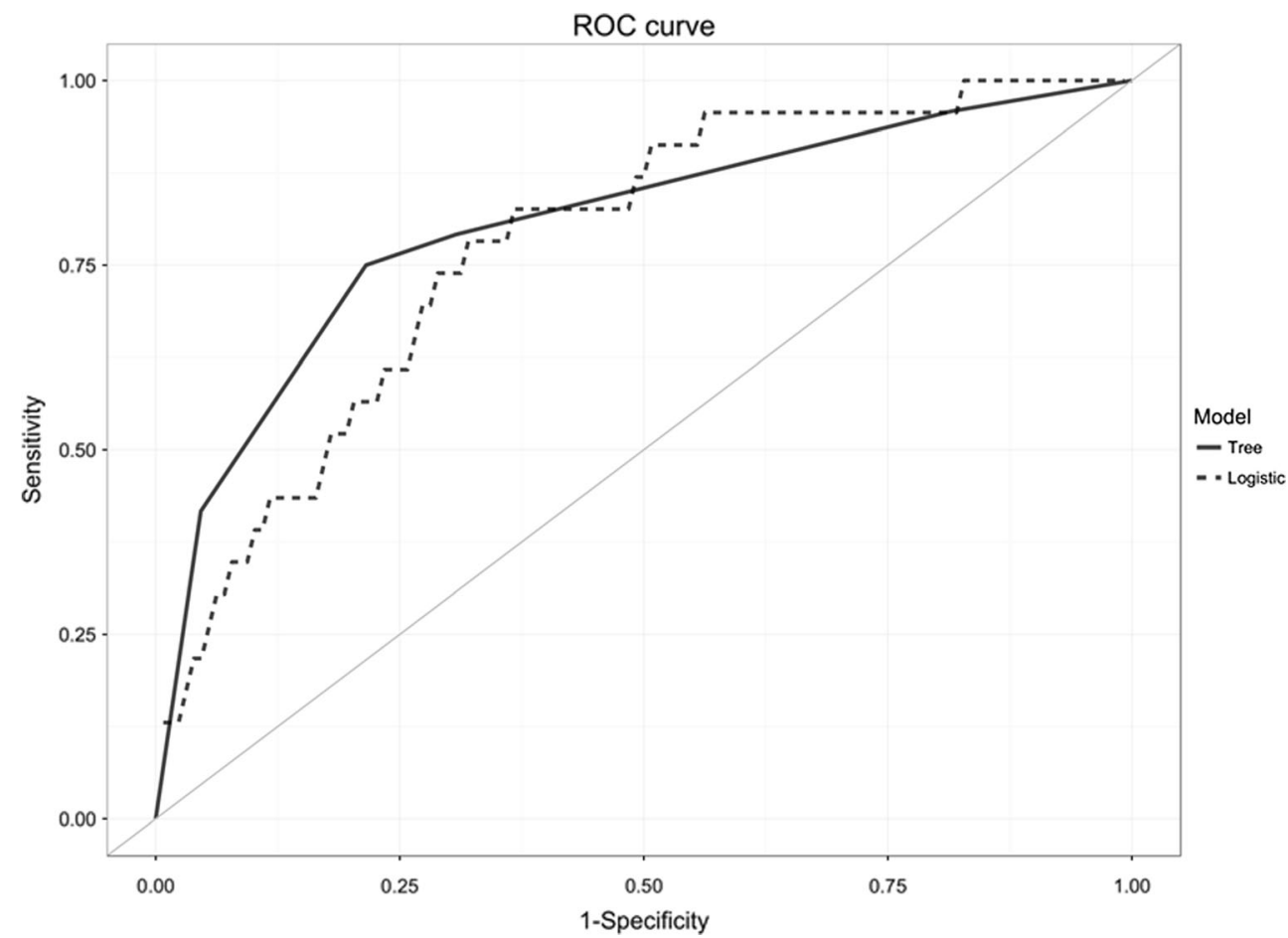


and should be validated on a larger pediatric cohort. The VALIGA data were collected retrospectively and a relevant bias could be related to missing cases not reported because of incomplete data. The choice of therapy was not standardized, drug exposure was not recorded in detail so the impact of dose and duration cannot be assessed. Larger cohorts are needed to derive definite conclusions on clinicopathological risk factors in children with IgAN. However, the limited enrolment rate in each center and the need for long term follow-up present almost insurmountable hurdles for the development of such a prospective multicenter large-scale collaborative study. This new statistical approach, applied to a cohort of young IgAN subjects, offers a previously unexplored means of generating clinically relevant information for physicians caring for patients with IgAN.

Acknowledgments The study was supported by a grant from the first research call of the European Renal Association-European Dialysis and Transplant Association (ERA-EDTA) in 2009. Stéphan Troyanov and John Feehally, members of the VALIGA Steering Committee are acknowledged for their helpful advice.

\section{Compliance with ethical standards}

Conflict of interest We declare that the results presented in this paper have not been published previously in whole or in part.

\section{VALIGA Centers}

Nephrologists V. Tesar, D. Maixnerova (Nephrology, First Faculty of Medicine and General University Hospital, Prague, Czech Republic); S. Lundberg (Nephrology, Karolinska University Hospital, Karolinska Institutet, Stockholm, Sweden); L. Gesualdo (Nephrology, Emergency and Organ Transplantation, University of Bari "Aldo Moro", FoggiaBari, Italy); F. Emma, L. Fuiano (Nephrology, Bambino Gesù Children's Hospital, Rome, Italy); G. Beltrame, C. Rollino (Nephrology, San Giovanni Bosco Hospital, Turin, Italy); R.Coppo, A.Amore, R.Camilla, L.Peruzzi (Nephrology, Regina Margherita Children's Hospital, Turin, Italy); D.Lofaro, T.Papalia, R.Bonofiglio (Kidney and Transplantation Research Centre, Nephrology, Dialysis and Transplantation, Annunziata Hospital, Cosenza, Italy); M. Praga (Nephrology, Hospital 12 de Octubre, Madrid, Spain); S. Feriozzi, R. Polci, (Nephrology, Belcolle Hospital, Viterbo, Italy); L. Biancone, L.Colla (Nephrology, S. Giovanni Battista University Hospital, Turin, Italy); A. Pani, A. Angioi, D. Piras (Nephrology, G. Brotzu Hospital, Cagliari, Italy); J. Feehally (John Walls Renal Unit, Leicester General Hospital, Leicester, United Kingdom); G. Cancarini, S. Ravera (Nephrology, Spedali Civili University Hospital, Brescia, Italy); M. Durlik (Transplantation Medicine and Nephrology, Warsaw Medical University, Warsaw, Poland); E. Moggia (Nephrology, Santa Croce Hospital, Cuneo, Italy); J. Ballarin (Nephrology, Fundacion Puigvert, Barcelona, Spain); S. Di Giulio (Nephrology, San Camillo Forlanini Hospital, Rome, Italy); A.Pierucci (Nephrology, Policlinico Umberto I University Hospital, Rome, Italy); Y. Caliskan, M.

Sever,(Nephrology, Internal Medicine, Istanbul Faculty of Medicine, Istanbul, Turkey); F.Locatelli, L. Del Vecchio (Nephrology, A. Manzoni Hospital, Lecco, Italy); J.F.M.Wetzels, H. Peters (Nephrology and Pathology, Radboud University Nijmegen Medical Center, Nijmegen, The Netherlands); U.Berg (Pediatrics, Department of Clinical Science, Intervention and Technology, Huddinge, Sweden); F. Carvalho, A.C. da Costa Ferreira (Nephrology, Hospital de Curry Cabral, Lisbon, Portugal); M. Maggio (Nephrology, Hospital Maggiore di Lodi, Lodi, Italy);
A.Wiecek, H.Karkoszka (Nephrology, Endocrinology and Metabolic Diseases, Silesian University of Medicine, Katowice, Poland); M. OtsRosenberg (Nephrology, Tartu University Clinics, Tartu, Estonia); R.Magistroni (Nephrology, Policlinic of Modena and Reggio Emilia; Modena, Italy); R.Topaloglu, Y.Bilginer (Pediatric Nephrology and Rheumatology, Hacettepe University, Ankara, Turkey); M.D’Amico (Nephrology, S. Anna Hospital, Como, Italy); M.Stangou (Nephrology, Hippokration General Hospital, Aristotle University of Thessaloniki, Thessaloniki, Greece); F.Giacchino (Nephrology, Ivrea Hospital, Ivrea, Italy); D.Goumenos, P.Kalliakmani, M.Gerolymos (Nephrology, University Hospital of Patras, Patras, Greece); K. Galesic (Nephrology, University Hospital Dubrava, Zagreb, Croatia); C.Geddes (Renal Unit, Western Infirmary Glasgow, Glasgow, United Kingdom);

K.Siamopoulos, O.Balafa (Nephrology, Medical School University of Ioannina, Ioannina, Greece); M. Galliani (Nephrology, S.Pertini Hospital, Rome, Italy); P.Stratta, M.Quaglia (Nephrology, Maggiore della Carità Hospital, Piemonte Orientale University, Novara, Italy); R.Bergia, R.Cravero (Nephrolgy, Degli Infermi Hospital, Biella, Italy);

M.Salvadori, L.Cirami (Nephrology, Careggi Hospital, Florence, Italy); B.Fellstrom, H.Kloster Smerud (Renal Department, University of Uppsala, Uppsala, Sweden); F. Ferrario, T. Stellato (Nephropathology, San Gerardo Hospital Monza, Italy); J. Egido, C. Martin Cleary (Nephrology, Fundacion Jimenez Diaz, Madrid, Spain); J. Floege, T. Rauen (Nephrology and Immunology, Medizinische Klinik II, University of Aachen, Aachen, Germany); A. Lupo, P. Bernich (Nephrology, University of Verona, Verona, Italy); P. Menè (Nephrology, S. Andrea Hospital, Rome, Italy); M. Morosetti (Nephrology, Grassi Hospital, Ostia, Italy); C. van Kooten, T. Rabelink, M.E.J. Reinders (Nephrology, Leiden University Medical Centre, Leiden, The Netherlands); J.M. Boria Grinyo (Nephrology, Hospital Bellvitge, Barcelona, Spain); S. Cusinato, L. Benozzi (Nephrology, Borgomanero Hospital, Borgomanero, Italy); S. Savoldi, C. Licata (Nephrology, Civile Hospital, Ciriè, Italy); M. Mizerska-Wasiak, M. Roszkowska-Blaim (Pediatrics and Nephrology, Medical University of Warsaw, Warsaw, Poland); G. Martina, A. Messuerotti (Nephrology, Chivasso Hospital, Chivasso, Italy); A. Dal Canton, C. Esposito, C. Migotto (Nephrology Units, S. Matteo Hospital and Maugeri Foundation, Pavia, Italy); G.Triolo, F.Mariano (Nephrology CTO, Turin, Italy); C.Pozzi (Nephrology, Bassini Hospital, Cinisello Balsamo, Italy); R. Boero (Nephrology, Martini Hospital, Turin, Italy)

Pathologists G.Mazzucco (Turin, Italy); C. Giannakakis (Rome, Italy); E. Honsova (Prague, Czech Republic); B. Sundelin (Stockholm, Sweden); A.M. Di Palma (Foggia-Bari, Italy); F. Ferrario (Monza, Italy); E. Gutiérrez (Madrid, Spain); A.M. Asunis (Cagliari, Italy); J. Barratt (Leicester, United Kingdom); R. Tardanico (Brescia, Italy); A. Perkowska-Ptasinska (Warsaw, Poland); J. Arce Terroba (Barcelona, Spain); M. Fortunato (Cuneo, Italy); A. Pantzaki (Thessaloniki, Greece); Y. Ozluk, I. Kilicaslan (Istanbul, Turkey); E. Steenbergen (Nijmegen, The Netherlands); M. Soderberg (Huddinge, Sweden); Z. Riispere (Tartu, Estonia); L. Furci (Modena, Italy); D. Orhan (Ankara, Turkey); D. Kipgen (Glasgow, United Kingdom); D. Casartelli (Lecco, Italy); D. Galesic Ljubanovic (Zagreb, Croatia); H Gakiopoulou (Athens, Greece), E. Bertoni (Florence, Italy); P. Cannata Ortiz (Madrid, Spain); H.

Karkoszka (Katowice, Poland), H.J. Groene (Heidelberg, Germany); A. Stoppacciaro (Rome, Italy); I. Bajema, J. Bruijn (Leiden,

The Netherlands); X. Fulladosa Oliveras (Barcelona, Spain); J. Maldyk (Medical University of Warsaw, Poland); E. Ioachim (Ioannina, Greece).

\section{References}

1. Coppo R (2008) Pediatric IgA nephropathy: clinical and therapeutic perspectives. Semin Nephrol 28:18-26

2. Wyatt RJ, Julian BA (2013) IgA nephropathy. N Engl J Med 368: 2402-2414 
3. Yamagata K, Iseki K, Nitta K, Imai H, Iino Y, Matsuo S, Makino H, Hishida A (2008) Chronic kidney disease perspectives in Japan and the importance of urinalysis screening. Clin Exp Nephrol 12:1-8

4. Coppo R, D'Amico G (2005) Factors predicting progression of IgA nephropathies. J Nephrol 18:503-512

5. Haas M, Rahman MH, Cohn RA (2008) IgA nephropathy in children and adults: comparison of histologic features and clinical outcomes. Nephrol Dial Transplant 23:2537-45

6. Fassbinder W, Brunner FP, Brynger H, Ehrich JH, Geerlings W, Raine AE, Rizzoni G, Selwood NH, Tufveson G, Wing AJ (1991) Combined report on regular dialysis and transplantation in Europe. Nephrol Dial Transplant 6:5-35

7. Shima Y, Nakanishi K, Hama T, Mukaiyama H, Togawa H, Sako M, Kaito H, Nozu K, Tanaka R, Iijima K, Yoshikawa N (2013) Spontaneous remission in children with IgA nephropathy. Pediatr Nephrol 28:71-76

8. Komatsu H, Fujimoto S, Sato Y, Hara S, Yamada K, Morita S, Eto T (2005) "Point of no return (PNR)" in progressive IgA nephropathy: significance of blood pressure and proteinuria management up to PNR. J Nephrol 18:690-695

9. Cattran DC, Coppo R, Cook HT, Feehally J, Roberts IS, Troyanov S, Alpers CE, Amore A, Barratt J, Berthoux F, Bonsib S, Bruijn JA, D'Agati V, D'Amico G, Emancipator S, Emma F, Ferrario F, Fervenza FC, Florquin S, Fogo A, Geddes CC, Groene HJ, Haas M, Herzenberg AM, Hill PA, Hogg RJ, Hsu SI, Jennette JC, Joh K, Julian BA, Kawamura T, Lai FM, Leung CB, Li LS, Li PK, Liu ZH, Mackinnon B, Mezzano S, Schena FP, Tomino Y, Walker PD, Wang H, Weening JJ, Yoshikawa N, Zhang H (2009) The Oxford classification of IgA nephropathy: rationale, clinicopathological correlations, and classification. Kidney Int 76:534-545

10. Roberts IS, Cook HT, Troyanov S, Alpers CE, Amore A, Barratt J, Berthoux F, Bonsib S, Bruijn JA, Cattran DC, Coppo R, D'Agati V, D'Amico G, Emancipator S, Emma F, Feehally J, Ferrario F, Fervenza FC, Florquin S, Fogo A, Geddes CC, Groene HJ, Haas M, Herzenberg AM, Hill PA, Hogg RJ, Hsu SI, Jennette JC, Joh K, Julian BA, Kawamura T, Lai FM, Li LS, Li PK, Liu ZH, Mackinnon B, Mezzano S, Schena FP, Tomino Y, Walker PD, Wang H, Weening JJ, Yoshikawa N, Zhang H (2009) The Oxford classification of IgA nephropathy: pathology definitions, correlations, and reproducibility. Kidney Int 76:546-56

11. Coppo R, Troyanov S, Camilla R, Hogg RJ, Cattran DC, Cook HT, Feehally J, Roberts IS, Amore A, Alpers CE, Barratt J, Berthoux F, Bonsib S, Bruijn JA, D'Agati V, D'Amico G, Emancipator SN, Emma F, Ferrario F, Fervenza FC, Florquin S, Fogo AB, Geddes CC, Groene HJ, Haas M, Herzenberg AM, Hill PA, Hsu SI, Jennette JC, Joh K, Julian BA, Kawamura T, Lai FM, Li LS, Li PK, Liu ZH, Mezzano S, Schena FP, Tomino Y, Walker PD, Wang H, Weening JJ, Yoshikawa N, Zhang H (2010) The Oxford IgA nephropathy clinicopathological classification is valid for children as well as adults. Kidney Int 77:921-7

12. Shima $Y$, Nakanishi K, Hama T, Mukaiyama H, Togawa H, Hashimura Y, Kaito H, Sako M, Iijima K, Yoshikawa N (2012) Validity of the Oxford classification of IgA nephropathy in children. Pediatr Nephrol 27:783-92

13. Le W, Zeng CH, Liu Z, Liu D, Yang Q, Lin RX, Xia ZK, Fan ZM, Zhu G, Wu Y, Xu H, Zhai Y, Ding Y, Yang X, Liang S, Chen H, Xu F, Huang Q, Shen H, Wang J, Fogo AB, Liu ZH (2012) Validation of the Oxford classification of IgA nephropathy for pediatric patients from China. BMC Nephrol 13:158

14. Edström Halling S, Söderberg MP, Berg UB (2012) Predictors of outcome in paediatric IgA nephropathy with regard to clinical and histopathological variables (Oxford classification). Nephrol Dial Transplant 27:715-22

15. Bjørneklett R, Vikse BE, Bostad L, Leivestad T, Iversen BM (2011) Long-term risk of ESRD in IgAN; validation of Japanese prognostic model in a Norwegian cohort. Nephrol Dial Transplant 27:1485-91

16. Higa A, Shima $Y$, Hama $T$, Sato $M$, Mukaiyama $H$, Togawa $H$, Tanaka R, Nozu K, Sako M, Iijima K, Nakanishi K, Yoshikawa N (2015) Long-term outcome of childhood IgA nephropathy with minimal proteinuria. Pediatr Nephrol 30:2121-2127

17. Coppo R, Troyanov S, Bellur S, Cattran D, Cook HT, Feehally J, Roberts IS, Morando L, Camilla R, Tesar V, Lunberg S, Gesualdo L, Emma F, Rollino C, Amore A, Praga M, Feriozzi S, Segoloni G, Pani A, Cancarini G, Durlik M, Moggia E, Mazzucco G, Giannakakis C, Honsova E, Sundelin BB, Di Palma AM, Ferrario F, Gutierrez E, Asunis AM, Barratt J, Tardanico R, Perkowska-Ptasinska A, VALIGA study of the ERA-EDTA Immunonephrology Working Group, (2014) Validation of the Oxford classification of IgA nephropathy in cohorts with different presentations and treatments. Kidney Int 86:828-836

18. Sleeper LA, Harrington DP (1990) Regression splines in the cox model with application to covariate effects in liver disease. J Am Stat Assoc 85:941-949

19. Work DF, Schwartz GJ (2008) Estimating and measuring glomerular filtration rate in children. Curr Opin Nephrol Hypertens 17: $320-325$

20. Levey AS, Bosch JP, Lewis JB, Greene T, Rogers N, Roth D (1999) A more accurate method to estimate glomerular filtration rate from serum creatinine: a new prediction equation. Modification of Diet in Renal Disease Study Group. Ann Intern Med 130:461-470

21. Wühl E, Witte K, Soergel M, Mehls O, Schaefer F (2002) Distribution of 24-h ambulatory blood pressure in children: normalized reference values and role of body dimensions. J Hypertens 20: 1995-2007

22. Reich HN, Troyanov S, Scholey JW, Cattran DC, Registry TG (2007) Remission of proteinuria improves prognosis in IgA nephropathy. J Am Soc Nephrol 18:3177-83

23. Matsushita S, Ishikura K, Okamoto S, Okuda Y, Nagaoka Y, Harada R, Hamada R, Sakai T, Hamasaki Y, Hataya H, Ando T, Ogata K, Honda M (2015) Long-term morbidity of IgA nephropathy in children evaluated with newly proposed remission criteria in Japan. Clin Exp Nephrol 19:1149-56

24. Bou-Hamad I, Larocque D, Ben-Ameur H (2011) A review of survival trees. Stat Surv 5:44-71

25. Austin PC (2007) A comparison of the statistical power of different methods for the analysis of cluster randomization trials with binary outcomes. Stat Med 26:3550-65

26. Lofaro D, Jager KJ, Abu-Hanna A, Groothoff JW, Arikoski P, Hoecker B, Roussey-Kesler G, Spasojević B, Verrina E, Schaefer F, van Stralen KJ, ESPN/ERA-EDTA Registry (2015) Identification of subgroups by risk of graft failure after paediatric renal transplantation: application of survival tree models on the ESPN/ERA-EDTA Registry. Nephrol Dial Transplant 31:317-324

27. Hastings MC, Delos Santos NM, Wyatt RJ (2007) Renal survival in pediatric patients with IgA nephropathy. Pediatr Nephrol 22:317-318

28. Ronkainen J, Ala-Houhala M, Autio-Harainen $\mathrm{H}$, Jahnukainen $\mathrm{T}$, Koskimies O, Merenmies J, Mustonen J, Ormälä T, Turtinen J, Nuutinen M (2006) Long-term outcome 19 years after childhood IgA nephritis: a retrospective cohort study. Pediatr Nephrol 21: 1266-1273

29. Barbour SJ, Espino-Hernandez G, Reich HN, Coppo R, Roberts IS, Feehally J, Herzenberg AM, Cattran DC, VALIGA; OXFORD DERIVATION AND NORTH AMERICAN VALIDATION (2016) The MEST score provides earlier risk prediction in IgA nephropathy. Kidney Int 89:167-75

30. Vandenbroucke JP, von Elm E, Altman DG, Gøtzsche PC, Mulrow CD, Pocock SJ, Poole C, Schlesselman JJ, Egger M, Initiative STROBE (2014) Strengthening the Reporting of Observational Studies in Epidemiology (STROBE): explanation and elaboration. Int J Surg 12:1500-2 